\title{
Extracellular Polymeric Substances of Pseudomonas chlororaphis 06 Induce Systemic Drought Tolerance in Plants
}

\author{
*Corresponding author \\ Tel: +82-62-530-2071 \\ Fax: +82-62-530-0208 \\ E-mail:yckimyc@chonnam.ac.kr \\ ORCID \\ https://orcid.org/0000-0002-7661-7600
}

\author{
Song Mi Cho ${ }^{1}$, Anne J. Anderson ${ }^{2}$, and Young Cheol Kim $\mathbb{1 0}^{3 *}$ \\ ${ }^{1}$ Department of Floriculture, Chunnam Techno University, Jeonnam 57500, Korea \\ ${ }^{2}$ Department of Biological Engineering, Utah State University, Logan, UT 84322-5305, USA \\ ${ }^{3}$ Institute of Environmentally-Friendly Agriculture, Department of Plant Biotechnology, \\ Chonnam National University, Gwangju 61186, Korea
}

Received August 13, 2018

Revised August 20, 2018

Accepted August 20, 2018

\begin{abstract}
Pseudomonas chlororaphis $\mathrm{O} 6$ induces systemic tolerance in plants against drought stress. A volatile, 2R, 3R-butanediol, produced by the bacterium causes partial stomatal closure, thus, limiting water loss from the plant. In this study, we report that applications of extracellular polymeric substances (EPS) from $P$. chlororaphis O6 to epidermal peels of leaves of Arabidopsis thaliana also reduce the size of stomatal openings. Growth of A. thaliana seedlings with applications of the EPS from $P$. chlororaphis $\mathrm{O} 6$ reduced the extent of wilting when water was withheld from the plants. Fluorescence measurements showed photosystem II was protected in the $A$. thaliana leaves in the water stressed EPS-exposed plants. These findings indicate that $P$. chlororaphis $\mathrm{O} 6$ has redundancy in traits associated with induction of mechanisms to limit water stress in plants.
\end{abstract}

Keywords: Abiotic stress, Biological control, Priming, Stomatal closure
Plant possess elegant and effective survival systems against abiotic stress and biotic invasion (Zhu, 2001). Under drought conditions, the level of the plant hormone, abscisic acid (ABA) increases, triggering adaptive responses that are essential for the survival of plants (Zhu, 2001). One effect of the enhanced ABA level is stomatal closure that minimizes water loss through transpiration (Leung and Giraudat, 1998). Consequently, because of the problems associated with the regulation of stomatal aperture, plants with defects in ABAbiosynthesis (aba mutants) and ABA-responses (i.e., ABAinsensitive abi mutants) are susceptible to drought stress (Leung and Giraudat, 1998; Schroeder et al., 2001). Another plant growth regulator, jasmonate (Evans, 2003; Suhita et al., 2004), also stimulates stomatal closure under drought conditions (Creelman and Mullet, 1997).

Research in Plant Disease

pISSN 1598-2262, elSSN 2233-9191

www.online-rpd.org
In plants, drought tolerance can be induced upon colonization by certain microbes. Pseudomonas chlororaphis 06, a plant probiotic microbe (Kim and Anderson, 2018), elicits both induced systemic resistance (ISR) to pathogens and induced systemic tolerance (IST) to environmental stresses (Kim et al., 2011; Yang et al., 2009, 2017). Induced tolerance to drought in plants also occurs with colonization by several Gram-positive Bacillus strains (Ryu et al., 2004; Timmusk and Wagner, 1999; Zhang et al., 2010), other Gram-negative bacterial isolates (Mayak et al., 2004), and fungi such as Trichoderma harziarum (Bae et al., 2008; Shukla et al., 2015). The volatile $2 \mathrm{R}, 3 \mathrm{R}$-butanediol is a metabolite produced by the plant-associated bacteria strains that causes stomatal closure and induces the expression of genes promoting drought tolerance (Kim et al., 2012). Butanediol-induced drought tolerance in Arabidopsis involves activation of salicylic acid (SA), jasmonic acid, and ethylene-dependent pathways (Cho et al., 2008).

Recent reviews indicate that there is an array of different 
types of microbial determinants inducing systemic tolerance in plants against biotic and/or abiotic stresses (Bakker et al., 2013; Cheng et al., 2017; Kim and Anderson, 2018). Some of the determinants have been identified by examining mutants in root-colonizing beneficial microbes impaired in their abilities to cause IST (Cheng et al., 2017; Han et al., 2006; Kim et al., 2007). The active microbial structures include such secreted metabolites (Kim and Anderson, 2018) as antibiotics, siderophores, and organic volatiles (e.g. butanediol) and bacterial surface structures, the lipopolysaccharides and flagella proteins (Melotto et al., 2006; Underwood et al., 2007). These findings illustrate that a single microbe may produce several factors that will cause IST.

We observed that induced drought tolerance by P. chlororaphis $\mathrm{O} 6$ correlates with decreased stomatal aperture size on the leaf in plants with roots colonized by this microbe (Cho et al., 2008). In this study, we extend the knowledge of microbial products inducing tolerance to drought to include the extracellular polymeric substances (EPS) from P. chlororaphis O6. The potential of EPS to induce drought tolerance was studied by determining whether they caused stomatal closure in the epidermal peels. At the whole plant level, the extent of wilting upon withholding water was assessed by visual comparison between plants with and without EPS treatments. The extent of drought was also characterized by measuring the chlorophyll fluorescence in the leaf tissues (Woo et al., 2008). Drought causes changes in the photosynthetic potential of plants that can be detected by measuring the $F_{v} / F_{m}$ ratio (Woo et al., 2008).

Isolation of EPS from P. chlororaphis 06. Cells from a single colony of $P$. chlororaphis $\mathrm{O6}$, grown for $2 \mathrm{~d}$ on LuriaBroth (LB, Difco Inc., Detroit, MI, USA) agar plates, were inoculated into $500 \mathrm{ml}$ of LB broth and incubated at room temperature for $4 \mathrm{~d}$ with agitation at $250 \mathrm{rpm}$. The EPS of $P$. chlororaphis $\mathrm{O} 6$ were isolated using a modified ethanol precipitation method as described previously (Hung et al., 2005). The bacterial cells were removed by centrifugation for $10 \mathrm{~min}$, and 30 Anson unit protease $(0.5 \mathrm{mg} / \mathrm{l}$, Quiagen Inc., Valencia, CA, USA) was added to the supernatant and incubated at $37^{\circ} \mathrm{C}$ for $12 \mathrm{~h}$ with agitation at $70 \mathrm{rpm}$. Ethanol was added to the supernatant to produce a $1: 4(\mathrm{v} / \mathrm{v})$ mixture of the supernatant:ethanol and stirred at $4^{\circ} \mathrm{C}$ for $14 \mathrm{~h}$. The precipitate was removed by filtration through a $0.2 \mu \mathrm{m}$ Millipore membrane. The precipitate was dissolved in sterile water and mixed with ethanol (1:4 ratio) at $4^{\circ} \mathrm{C}$ for $14 \mathrm{~h}$. The EPS were pelleted by centrifugation for $15,000 \times g$ at $4^{\circ} \mathrm{C}$ for $30 \mathrm{~min}$. The pellet was dried at room temperature for $5 \mathrm{~h}$ and the mass measured before dissolving in sterile distilled water to produce solutions with known mass $/ \mathrm{ml}$. The final EPS preparation was streaked on LB agar plate to confirm no contamination by any culturable microbes.

Data were analyzed by ANOVA $(p<0.01)$, using SPSS (version 23, SPSS Inc., Chicago, IL, USA) and if the value of the $F$ was significant, differences between each measurement were further elucidated through Duncan's multiple range test $(p<0.01)$.

\section{Examination of stomatal opening on epidermal peels.}

To determine the direct effects of EPS on stomatal opening, plants were grown in well plates for 4 weeks. Arabidopsis thaliana Col-O seeds were surfaced-sterilized with $0.3 \%$ sodium hypochlorite, followed by extensive washing with sterile water. Seeds were transferred to well plates (12-well microtiter plates; SPL Inc., Seoul, South Korea) that contained half-strength Murashige and Skoog salt (MS, Sigma-Aldrich, St. Louis, MO, USA) medium, $0.3 \%$ Phytagel and 3\% sucrose (pH 5.7) (Cho et al., 2008, 2012). The plates were sealed with Parafilm to prevent drying and no additional water was added during their growth. To maximize stomatal opening, the plants were maintained under light for at least $3 \mathrm{~h}$ before excising the epidermal peels. The peels were transferred on to glass slides. The cuticle side was treated with water (a negative control), defined dilutions of the EPS solution (10, 100 , and $1000 \mu \mathrm{g} / \mathrm{ml}$, the test treatments), or a suspension of P. chlororaphis $\mathrm{O} 6$ cells (a positive control). Another positive control for stomatal closure was treatment with $100 \mu \mathrm{M}$ ABA (Sigma-Aldrich). Two hours after incubation, the stomatal apertures were observed by light microscopy (Leica M165 FC, Leica Microsystems, Wetzlar, Germany). The size of the openings was assessed using the image acquisition software, Image-Pro (version 2.32 for Windows, Media Cybermetics, Rockville, MD, USA). At least 100 stomata/plants were counted, with five plants per treatment being used in each experimental replicate.

The treatment of leaf epidermal peels with $A B A$ and with the suspension of intact $P$. chlororaphis $\mathrm{O} 6$ cells decreased the size of stomatal aperture relative to stomata treated exclusively with water (Fig. 1A). These findings were expected based on the previous findings (Cho et al., 2008). Stomatal 

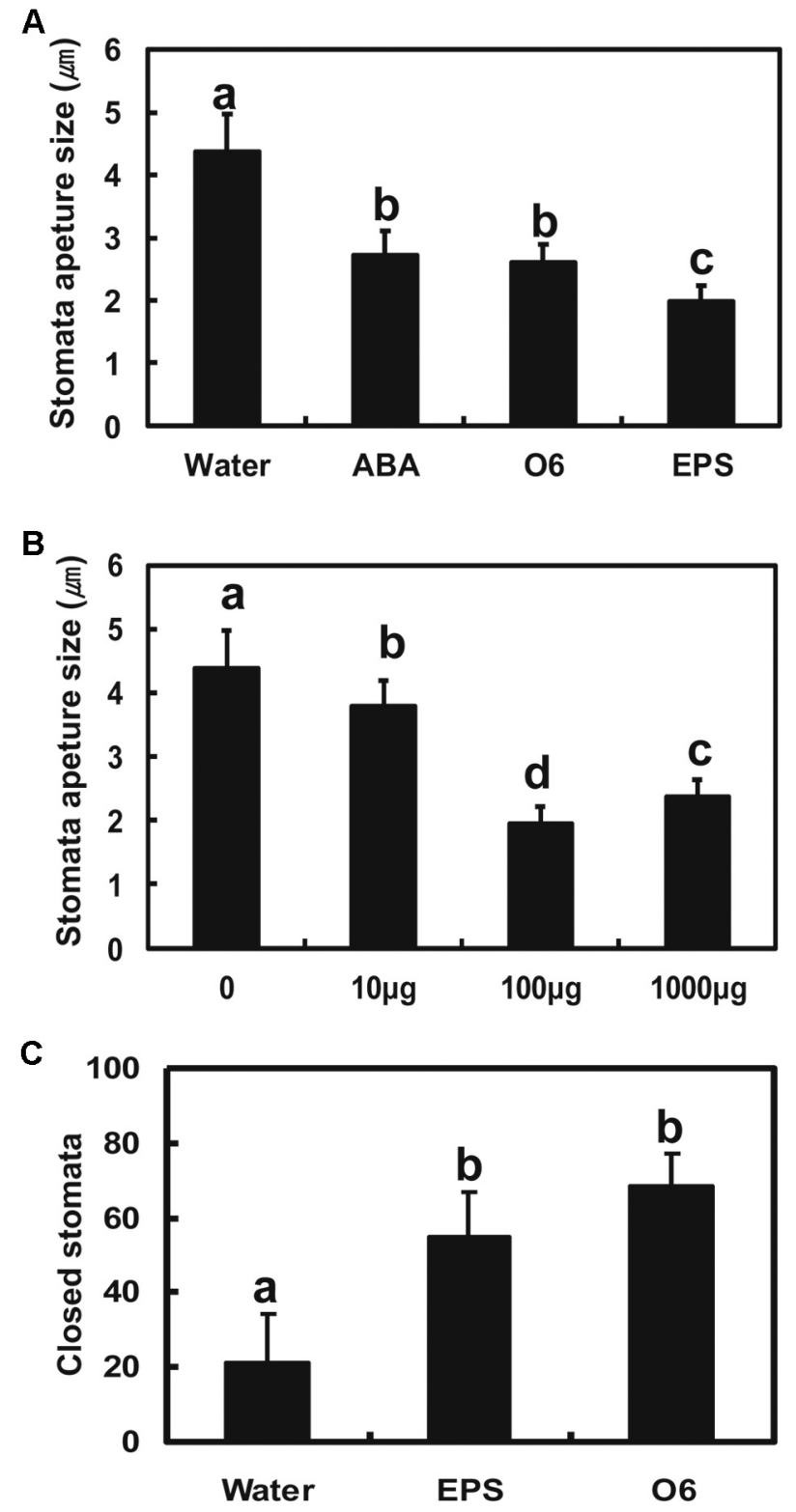

Fig. 1. Stomatal closure in epidermal peels by treatments with Pseudomonas chlororaphis $\mathrm{O6}$ cells, its EPS and ABA. The treatments for $2 \mathrm{~h}$ were $(\mathrm{A})$ : water; $100 \mu \mathrm{M}$ abscisic acid (ABA), or $P$. chlororaphis O6 cells $\left(1 \times 10^{8} \mathrm{cfu} / \mathrm{ml}\right)$ applied to the peel in $10 \mu$ laliquots and EPS $(100 \mu \mathrm{g} / \mathrm{ml})$ in (B) water or P. chlororaphis O6 EPS at defined concentrations. The width of the stomatal apertures was measured from light microscope images using the software Image-Pro C. (C) The $\%$ closed stomates with treatments of water, EPS $(100 \mu \mathrm{g} / \mathrm{ml})$ or $P$. chlororaphis 06 cells $\left(1 \times 10^{8} \mathrm{cfu} / \mathrm{ml}\right)$. At least 100 stomata per plant were counted, with five plants per treatment used in each experimental replicate. Different letters indicate significant differences between treated and control samples based on Duncan's multiple range test at $p<0.01$.

closure also was observed with treatment of $100 \mu \mathrm{g} / \mathrm{ml}$ EPS solution (Fig. 1A-C). The extent of closure was dose-dependent (Fig. 1B); when doses of 10, 100, and $1000 \mu \mathrm{g} / \mathrm{ml}$ were used, the $100 \mu \mathrm{g} / \mathrm{ml}$ treatment was optimal.

Plant wilting bioassay. To determine whether the treatments that caused the narrowing of stomatal openings corresponded with drought tolerance, the degree of wilting was assessed visually using $A$. thaliana seedlings grown in the well plates as described previously (Cho et al., 2008). The surface-sterilized seeds were placed on Whatman \# 1 paper and placed over the MS medium contained in the microtiter wells. The microtiter plates were sealed with parafilm to prevent drying. After two weeks of growth, the seedlings were treated with $10 \mu \mathrm{l} /$ plant, water as a control, $10 \mu \mathrm{l}$ per plant, P. chlororaphis $\mathrm{O} 6$ cell suspensions $\left(1 \times 10^{8} \mathrm{cfu} / \mathrm{ml}\right)$, or $10 \mu \mathrm{l}$ per plant, $100 \mu \mathrm{g} / \mathrm{ml}$ EPS solution. After $3 \mathrm{~d}$, seedlings on the filter papers were transferred to open, empty Petri dishes. The extent of wilting of the plants was assessed visually after $2 \mathrm{~h}$. The experiment was repeated three times with 12 plants per treatment.

When A. thaliana seedlings were exposed to the air, prior treatments for $3 \mathrm{~d}$ with EPS, or with live P. chlororaphis $\mathrm{O} 6$ cells, resulted in plants that exhibited less visible wilting than the plants treated with water as a control (Fig. 2A). Thus, $P$. chlororaphis $\mathrm{O} 6$ cells and extracted EPS reduced the wilt symptoms in intact plants deprived of water.

Quantitative assessment of drought survival using chlorophyll fluorescence. The changes in photosynthetic potential with drought were assessed with $A$. thaliana seedlings grown in sterile soil mix. The solid growth matrix was a sterile nursery soil mixture of Bio-Sangto, vermiculite, perlite (125 g/vessel, 3:1:1; Seminis Korea, Seoul, Korea) contained in sterile Magenta boxes $(10 \mathrm{~cm} \times 10 \mathrm{~cm} \times 9 \mathrm{~cm}$, Sigma-Aldrich). Five milliliters of water were added daily to the boxes. The seedlings were grown under a $16 \mathrm{~h} / 8 \mathrm{~h}$ light/dark cycle with 40-W fluorescent lights $\left(3,000 \mathrm{~lx}, 80 \mu \mathrm{mol}\right.$ photon $\left.\mathrm{m}^{-2} \mathrm{~s}^{-1}\right)$. The temperature was maintained at $23 \pm 2^{\circ} \mathrm{C}$ with a relative humidity of $50-60 \%$.

The seedlings were grown for 3 weeks before treatment with $2 \mathrm{ml}$ of sterile water as a negative control, or with equal volumes of $100 \mu \mathrm{M} \mathrm{ABA}$ as a positive control, or $P$. chlororaphis O6 EPS (100 $\mu \mathrm{g} / \mathrm{ml})$. A subset of the seedlings was drought-stressed by withholding water. After $12 \mathrm{~d}$ of drought stress, the chlorophyll fluorescence in the leaf tissues was measured using a Phyto-PAM (Heinz-Walz GmbH, Effeltrich, Germany) as described previously (Woo et al., 


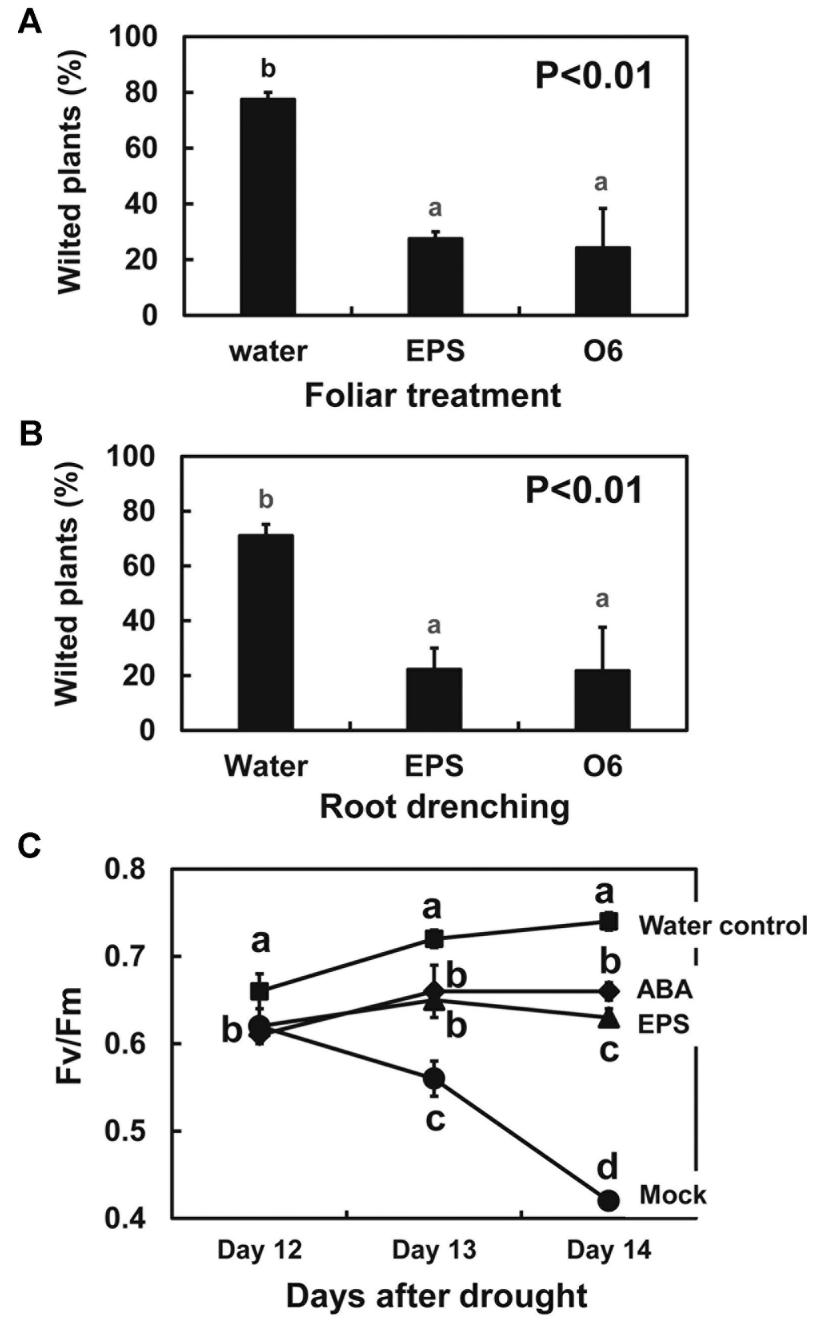

Fig. 2. Protective effects of Pseudomonas chlororaphis $\mathrm{O} 6$ and its EPS against drought stress in Arabidopsis thaliana Col-0 seedlings grown in MS agar. The seedlings leaves (A) and roots (B) were treated with water (Water) as a control, P. chlororaphis O6 cells (O6, $\left.1 \times 10^{8} \mathrm{cfu} / \mathrm{ml}\right)$, or $100 \mu \mathrm{g} / \mathrm{ml}$ EPS. The extent of wilting of the plants deprived of water was assessed visually after $2 \mathrm{~h}$. The study was performed three times with 12 plants per treatment. (C) Change in the $\mathrm{Fv} / \mathrm{Fm}$ value of leaves of $A$. thaliana $\mathrm{Col}-0$ plants raised in sterile soil mix. A subset of the plants had water withheld for $15 \mathrm{~d}$ whereas the control set had normal watering (water control). Treatments were water (mock), $100 \mu \mathrm{M}$ ABA or EPS $(100 \mu \mathrm{g} / \mathrm{ml})$. The fluorescence measurements were recorded daily to compare the $\mathrm{Fv} / \mathrm{Fm}$ values. The study was performed two times with 3 plants per treatment. The data presented are means and standard deviation from two studies. Different letters indicate significant differences between treated and control samples based on Duncan's multiple range test at $p<0.01$.

2008). The $F_{v} / F_{m}$ was determined by the application of a single saturating pulse to dark-adapted leaves for $30 \mathrm{~min}$ and used as a quantitative measure of drought tolerance (Woo et al., 2008). The experiment was repeated twice with 3 plants per treatment.

In plants grown in pot cultures that were maintained with normal hydration, the $F_{v} / F_{m}$ value for the leaves increased daily, indicating healthy photosynthesizing leaves (Fig. 2B). In plants that were subjected to drought stress by withholding water, the $F_{v} / F_{m}$ value steadily declined with the number of days of stress due to the impaired functioning of photosystem II. However, plants that were subjected to water withholding when treated with either ABA or EPS had leaves that showed no reduction in the $F_{m} / F_{v}$ values (Fig. 2B). This response was expected, because the partial closure of the stomata maintained function of photosystem II. Thus, treatments of the intact plants with the EPS from $P$. chlororaphis was as effective as ABA in protecting the plant from reduced photosynthetic efficacy under drought stress.

The present study indicated that the ethanol-precipitated EPS from $P$. chlororaphis $\mathrm{O} 6$ were effective in inducing protection against drought, as measured by limited wilting and by the maintenance of photosynthetic efficacy upon water withholding in intact Arabidopsis plants. Leaf tissues exposed to the EPS showed stomatal closure eliciting the same plant response as 2R, 3R-butanediol (Cho et al., 2008, 2013). Consequently, we demonstrated that EPS from $P$. chlororaphis $\mathrm{O} 6$ is another plant immune effector activating drought tolerance.

The EPS are part of the matrix that embeds bacterial cells in biofilms (Anderson and Kim, 2018). The composition of EPS likely includes different polysaccharides and extracellular DNA (Hung et al., 2005; Wingender et al., 1999). $P$. chlororaphis $\mathrm{O} 6$ forms patchy but layered and complex biofilms on roots as part of the surface colonization process (Bonebrake et al., 2018). Timmusk et al. (2015), based on their work with root-colonizing Gram-positive bacteria that active IST, concluded that the biofilm formation is required in induction of drought tolerance. Thus, the EPS produced in the root surface biofilms may be part of the microbial "microbe-associated molecular patterns" (MAMPs) that activate plant immunity. Indeed, EPS from Bacillus cereus acts as a MAMP for stimulating plant disease resistance (Jiang et al., 2016). We are currently characterizing the components in the EPS from P. chlororaphis O6. An interesting question is whether alginate is present. Alginate present in the EPS from $P$. aeruginosa, xanthan from Xanthomonas campestris, and amylovoran from Erwinia amylovora suppress plant immunity by binding calcium, thus, preventing MAMPinduced signaling in the plant host (Aslam et al., 2008). 
The EPS from P. chlororaphis $\mathrm{O} 6$ functions similarly to the EPS from other plant-associated bacteria, e.g., Pantoea agglomerans, Burkholderia gladioli, and P. putida, in the activation of defense mechanisms (Ortmann et al., 2006; Park et al., 2008; Sandhya et al., 2009; Santaella et al., 2008). These findings suggest that it is feasible to develop formulations containing EPS from certain plant-associated bacteria as "green formulations" to boost plant health during crop production. Such formulations would overcome the problem of requiring live microbial cells to induce stress tolerance. Applications of EPS-based formulations maybe especially valuable to aid in alleviating the stress imposed on crops by water shortage caused by higher temperatures and altered precipitation due to climate change.

\section{Conflicts of Interest}

No potential conflict of interest relevant to this article was reported.

\section{Acknowledgments}

This study was financially supported by a grant (314084-03) from the Korea Institute of Planning and Evaluation for Technology in Food, Agriculture, Forestry, and Fisheries, Ministry for Food, Agriculture, Forest, and Fisheries, South Korea.

\section{References}

Anderson, A. J. and Kim, Y. C. 2018. Biopesticides produced by plant-probiotic Pseudomonas chlororaphis isolates. Crop Prot. 105: 62-69.

Aslam, S. N., Newman, M. A., Erbs, G., Morrissey, K. L., Chinchilla, D., Boller, T. et al. 2008. Bacterial polysaccharides suppress induced innate immunity by calcium chelation. Curr. Biol. 18: 1078-1083.

Bae, H., Kim, S. H., Kim, M. S., Sicher, R. C., Lary, D., Strem, M. D. et al. 2008. The drought response of Theobroma cacao (cacao) and the regulation of genes involved in polyamine biosynthesis by drought and other stresses. Plant Physiol. Biochem. 46: 174-188.

Bakker, P. A. H. M., Doornbos, R. F., Zamioudis, C., Berendsen, R. L. and Pieterse, C. M. J. 2013. Induced systemic resistance and the rhizosphere microbiome. Plant Pathol. J. 29: 136-143.

Bonebrake, M., Anderson, K., Valiente, J., Jacobson, A., McLean, J. E. Anderson, A. et al. 2018. Biofilms benefiting plants exposed to $\mathrm{ZnO}$ and $\mathrm{CuO}$ nanoparticles studied with a root-mimetic hollow fiber membrane. J. Agric. Food Chem. 66: 6619-6627.

Cheng, X., Etalo, D. W., van de Mortel, J. E., Dekkers, E., Nguyen, L., Medema, M. H. et al. 2017. Genome-wide analysis of bacterial determinants of plant growth promotion and induced systemic resistance by Pseudomonas fluorescens. Environ. Microbiol. 19: 4638-4656.

Cho, S. M., Kang, B. R., Han, S. H., Anderson, A. J., Park, J. Y., Lee, Y. H. et al. 2008. 2R, 3R-butanediol, a bacterial volatile produced by Pseudomonas chlororaphis $\mathrm{O6}$, is involved in induction of systemic tolerance to drought in Arabidopsis thaliana. Mol. Plant Microbe Interact. 21: 1067-1075.

Cho, S. M., Kang, B. R., Kim, J. J. and Kim, Y. C. 2012. Induced systemic drought and salt tolerance by Pseudomonas chlororaphis $\mathrm{O} 6$ root colonization is mediated by ABA-independent stomatal closure. Plant Pathol. J. 28: 202-206.

Cho, S. M., Kang, B. R. and Kim, Y. C. 2013. Transcriptome analysis of induced systemic drought tolerance elicited by Pseudomonas chlororaphis $\mathrm{O} 6$ in Arabidopsis thaliana. Plant Pathol. J. 29: 209220.

Creelman, R. A. and Mullet, J. E. 1997. Biosynthesis and action of jasmonate in plants. Annu. Rev. Plant Physiol. Plant Mol. Biol. 48: 355-381.

Evans, N. H. 2003. Modulation of guard cell plasma membrane potassium currents by methyl jasmonate. Plant Physiol. 131: 8-11.

Han, S. H., Anderson, A. J., Yang, K. Y., Cho, B. H., Kim, K. Y., Lee, M. C. et al. 2006. Multiple determinants influence root colonization and induction of induced systemic resistance by Pseudomonas chlororaphis O6. Mol. Plant Pathol. 7: 463-472.

Hung, C.-C., Santschi, P. H. and Gillow, J. B. 2005. Isolation and characterization of extracellular polysaccharides produced by Pseudomonas fluorescens Biovar II. Carbohydr. Polym. 61: 141147.

Jiang, C.-H., Fan, Z.-H., Xie, P. and Guo, J.-H. 2016. Bacillus cereus AR156 extracellular polysaccharides served as a novel microassociated molecular pattern to induced systemic immunity to Pst DC3000 in Arabidopsis. Front. Microbiol. 7: 664.

Kim, H. J., Nam, H. S., Anderson, A. J., Yang, K. Y., Cho, B. H. and Kim, Y. C. 2007. Mutation in the edd gene encoding the 6-phosphogluconate dehydratase of Pseudomonas chlororaphis 06 impairs root colonization and is correlated with reduced induction of systemic resistance. Lett. Appl. Microbiol. 44: 56-61.

Kim, Y. C., Leveau, J., McSpadden Gardener, B. B., Pierson, E. A., Pierson III, L. S. and Ryu, C. M. 2011. The multifactorial basis for plant health promotion by plant-associated bacteria. Appl. Environ. Microbiol. 77: 1548-1555.

Kim, Y. C., Glick, B. R., Bashan, Y. and Ryu, C. M. 2012. Enhancement of Plant Drought Tolerance by Microbes. In: Plant Responses to Drought Stress, ed. by R. Aroca, pp. 383-413. Springer, Berlin, Germany.

Kim, Y. C. and Anderson, A. J. 2018. Rhizosphere pseudomonads as probiotics improving plant health. Mol. Plant Pathol. doi:10.1111/ mpp.12693.

Leung, J. and Giraudat, J. 1998. Abscisic acid signal transduction Annu. Rev. Plant Physiol. Plant Mol. Biol. 49: 199-222.

Mayak, S., Tirosh, T. and Glick, B. R. 2004. Plant growth-promoting 
bacteria confer resistance in tomato plants to salt stress. Plant Physiol. Biochem. 42: 565-572.

Melotto, M., Underwood, W., Koczan, J., Nomura, K. and He, S. Y. 2006. Plant stomata function in innate immunity against bacterial invasion. Cell 126: 969-980.

Ortmann, I., Conrath, U. and Moerschbacher, B. M. 2006. Exopolysaccharides of Pantoea agglomerans have different priming and eliciting activities in suspension-cultured cells of monocots and dicots. FEBS Lett. 580: 4491-4494.

Park, K., Kloepper, J. W. and Ryu, C. M. 2008. Rhizobacterial exopolysaccharides elicit induced resistance on cucumber. J. Microbiol. Biotechnol. 18: 1095-1100.

Ryu, C. M., Farag, M. A., Hu, C. H., Reddy, M. S., Kloepper, J. W. and Paré, P. W. 2004. Bacterial volatiles induce systemic resistance in Arabidopsis. Plant Physiol. 134: 1017-1026.

Sandhya, V., Ali, S. Z., Grover, M., Reddy, G. and Venkateswarlu, B. 2009. Alleviation of drought stress effects in sunflower seedlings by the exopolysaccharides producing Pseudomonas putida strain GAP-P45. Biol. Fert. Soils 46: 17-26.

Santaella, C., Schue, M., Berge, O., Heulin, T. and Achouak, W. 2008. The exopolysaccharide of Rhizobium sp. YAS34 is not necessary for biofilm formation on Arabidopsis thaliana and Brassica napus roots but contributes to root colonization. Environ. Microbiol. 10: 2150-2163.

Schroeder, J. I., Kwak, J. M. and Allen, G. J. 2001. Guard cell abscisic acid signalling and engineering drought hardiness in plants. Nature 410: 327-330.

Shukla, N., Awasthi, R. P., Rawat, L. and Kumar, J. 2015. Seed biopriming with drought tolerant isolates of Trichoderma harzianum promote growth and drought tolerance in Triticum aestivum. Ann. Appl. Biol. 166: 171-182.
Suhita, D., Raghavendra, A. S., Kwak, J. M. and Vavasseur, A. 2004. Cytoplasmic alkalization precedes reactive oxygen species production during methyl jasmonate- and abscisic acid-induced stomatal closure. Plant Physiol. 134: 1536-1545.

Timmusk, S. and Wagner, E. G. 1999. The plant-growth-promoting rhizobacterium Paenibacillus polymyxa induces changes in Arabidopsis thaliana gene expression: a possible connection between biotic and abiotic stress responses. Mol. Plant Microbe Interact. 12: 951-959.

Underwood, W., Melotto, M. and He, S. Y. 2007. Role of plant stomata in bacterial invasion. Cell. Microbiol. 9: 1621-1629.

Wingender, J., Neu, T. R. and Flemming, H.-C. 1999. What are bacterial extracellular polymeric substances? In: Microbial Extracellular Polymeric Substances, eds. by J. Wingender, T. R. Neu and H.-C. Flemming, pp. 1-19. Springer, Berlin, Germany.

Woo, N. S., Badger, M. R. and Pogson, B. J. 2008. A rapid, non-invasive procedure for quantitative assessment of drought survival using chlorophyll fluorescence. Plant Methods 4: 27.

Yang, J., Kloepper, J. W. and Ryu, C. M. 2009. Rhizosphere bacteria help plants tolerate abiotic stress. Trends Plant Sci. 14: 1-4.

Yang, K.-Y., Doxey, S., McLean, J. E., Britt, D., Watson, A., Al Qassy, D. et al. 2017. Remodeling of root morphology by $\mathrm{CuO}$ and $\mathrm{ZnO}$ nanoparticles: effects on drought tolerance for plants colonized by a beneficial pseudomonad. Botany 96: 175-186.

Zhang, H., Murzello, C., Sun, Y., Kim, M. S., Xie, X., Jeter, R. M. et al. 2010. Choline and osmotic-stress tolerance induced in Arabidopsis by the soil microbe Bacillus subtilis (GB03). Mol. Plant Microbe Interact. 23: 1097-1104.

Zhu, J. K. 2001. Cell signaling under salt, water and cold stresses. Curr. Opin. Plant Biol. 4: 401-406. 